\title{
Portal vein variations in Sri Lankan patients: a computed tomographic imaging based study
}

\author{
Joel Arudchelvam \\ Teaching Hospital Anuradhapura, Sri Lanka
}

Key words: Portal vein branching variations; types of portal vein variation; portal vein

\begin{abstract}
Knowledge about portal vein (PV) branch anatomy variations is essential in preventing disastrous complications following liver surgeries. Case series among Sri Lankan patients reporting variations in PV branching anatomy has not been published previously. This study reports a series of PV branch variations among patients who had a contrast-enhanced Computed Tomography (CT) is done at the Teaching Hospital Anuradhapura (THA). PV branching was classified into Types A - D. Primary PV branching variations occurred among $12.6 \%$ of patients. Type $\mathrm{C}$ variation was the commonest $(7.8 \%)$.
\end{abstract}

\section{Background}

Knowledge about the PV branch anatomy is essential in live donor liver transplantation, liver resection, transjugular intrahepatic portosystemic stent shunt insertion (TIPSS), portal vein embolization, etc. The primary PV branching pattern is reported to vary in $11 \%-21.5 \%$ of subjects even though this is less frequent than the hepatic arterial and hepatic venous anatomy variations (1-3). But detailed knowledge of the PV branching variations is important to plan the surgery and to avoid complications. No such case series of PV branching variations have been reported in Sri Lanka.

\section{Methods}

Abdominal contrast-enhanced CT scans showing PV phase, done at The THA Sri Lanka was evaluated over a 2 month period from October 2018 to November 2018. All the images were reviewed by the author at the computed tomography console room on the computer. Images showing artifacts, inadequate PV enhancement, the inadequate extent of imaging, intra/extra hepatic lesions distorting the PV anatomy were excluded. Primary PV branching variations were evaluated (main and sectoral branches).PV branching

Correspondence: Joel Arudchelvam

E-mail: joelaru@yahoo.com

Received: 10-02-2019 Accepted: 26-04-2019

(iD http://orcid.org/0000-0002-4371-4527

DOI: http://doi.org/10.4038/sljs.v37i1.8602

The Sri Lanka Journal of Surgery 2019; 37(1): 37 - 38 variations were classified as follows (figure 1)

PV branching variations were classified as follows (Figure 1).

- Type A (classical pattern)

Main PV divides into the right (RPV) and left (LPV) branches

- Type B (trifurcation)

The main PV divides into right anterior sectoral (RAPV), right posterior sectoral (RPPV) and LPV branches

- Type C (early RPPVbranching) $R P P V$ originates directly from the main $P V$ before it divides

- Type D

All other branching patterns

\section{Results}

PV anatomy was evaluated on 103 CT scans. There were 49 males $(47.6 \%)$ and 54 females. 90 cases showed classical anatomy (Type A- 87.4\%). Thirteen (12.6\%) cases showed variations in a primary branching pattern. Type $\mathrm{C}$ variation (early RPPV branching) was common and seen in 8 patients ( $7.8 \%$ ) while type $\mathrm{B}$ variation occurred in 3 subjects (2.9\%).Type D variation occurred in $2(1.9 \%)$. All patients who had type $B$ variation were females.

\section{Discussion}

PV originates by the confluence of splenic and superior mesenteric veins posterior the neck of the pancreas. It runs in the free edge of the lesser omentum and at the liver hilum, it divides into right and left branches (RPV and LPV) (Refer Figure 1). RPV further divides into an anterior sectoral (supplying segments V and VIII) and posterior sectoral (supplying segments VI and VII) branches. The LPV supplies segments II, III and IV and its anatomy is generally consistent. Previous studies reported that the variations occur at the rate of 11 to $21 \%(1,3)$. No such case series have been reported from Sri Lanka before.

Our study showed that the classical pattern of primary PV branching occurs in $87.4 \%$ and variations occur in $12.6 \%$. Various studies mention either type $\mathrm{B}$ or $\mathrm{C}$ as a common type of variation $(1,3)$. In our study type $C$ variation was common 

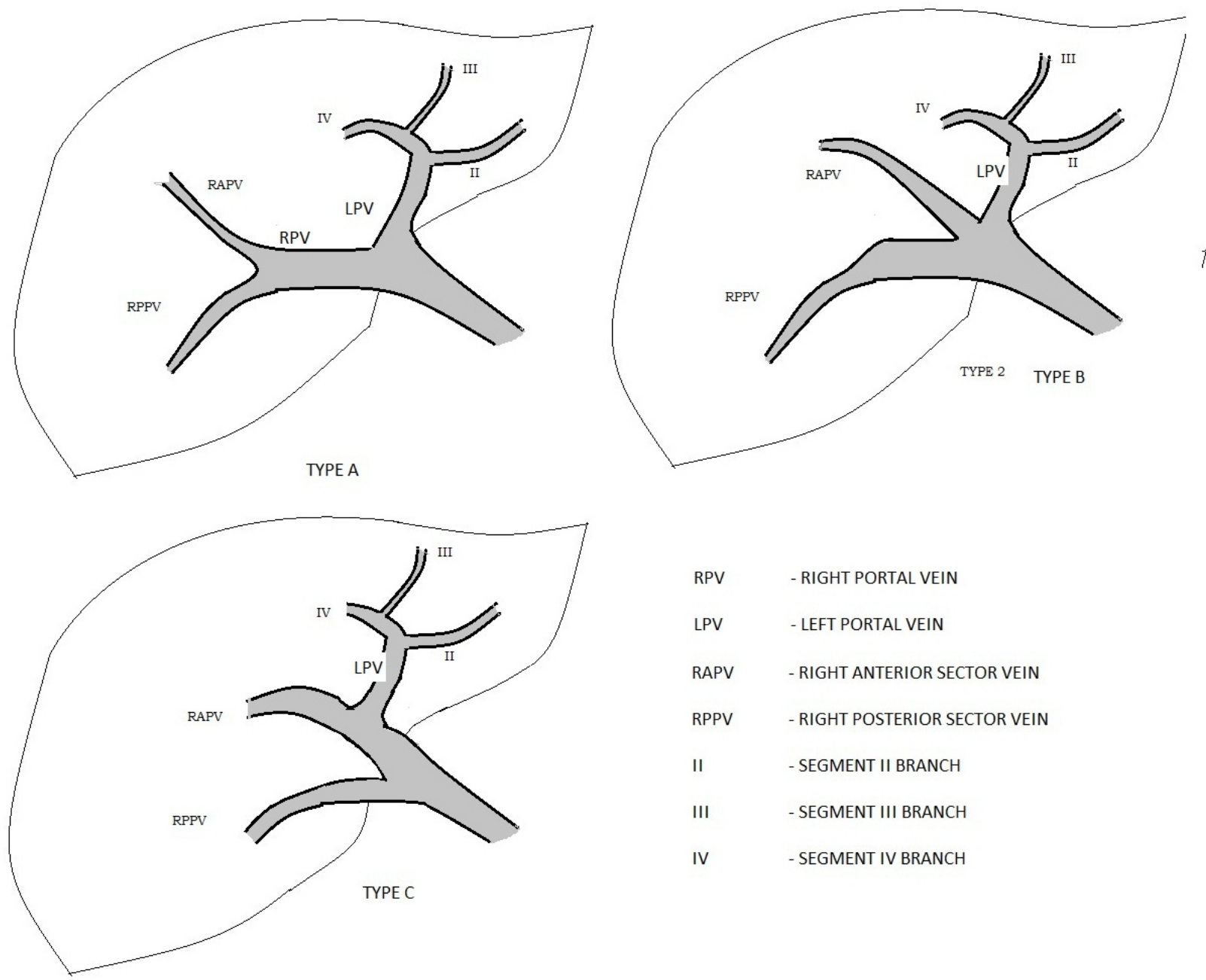

$\begin{array}{ll}\text { RPV } & \text { - RIGHT PORTAL VEIN } \\ \text { LPV } & \text { - LEFT PORTAL VEIN } \\ \text { RAPV } & \text { - RIGHT ANTERIOR SECTOR VEIN } \\ \text { RPPV } & \text { - RIGHT POSTERIOR SECTOR VEIN } \\ \text { II } & \text { - SEGMENT II BRANCH } \\ \text { III } & \text { - SEGMENT III BRANCH } \\ \text { IV } & \text { - SEGMENT IV BRANCH }\end{array}$

Figure 1. Portal Vein Branching Variations

(7.8\%). Knowledge about the existence of portal vein branching variations is essential to plan the surgeries and radiological interventions and also to prevent complications.

The limitations of this study include the small study size number and also type $\mathrm{D}$ variations were not further categorized. In addition all the images were read by a nonradiologist, though experienced vascular surgeon, which could be a drawback when non-anatomical concerns arise i.e. artifacts, timing of images, etc. Future studies either radiological or cadaveric can improve on these findings

All authors disclose no conflict of interest. The study was conducted in accordance with the ethical standards of the relevant institutional or national ethics committee and the Helsinki Declaration of 1975, as revised in 2000 .

\section{References}

1. Varotti G, Gondolesi GE, Goldman J, et al. Anatomic variations in right liver living donors. JAm Coll Surg 2004; 198:577-582. https://doi.org/10.1016/j.jamcollsurg.2003.11.014

2. Lee VS, Morgan GR, Lin JC, et al. Liver transplant donor candidates: associations between vascular and biliary anatomic variants. Liver Transpl 2004; 10:1049-1054 https://doi.org/10.1002/lt.20181

3. Koç Z1, Oğuzkurt L, Ulusan S. Portal vein variations: clinical implications and frequencies in routine abdominal multidetector CT.Diagn Interv Radiol. 2007 Jun; 13(2):75-80. PMID: 17562511 